\title{
Teaching-Learning Process of Architecture Workshops in Virtual Environments Based on Research-Action Methodology
}

\author{
Nataly Revelo Morales ${ }^{1}$, Álvaro Guzmán Rodríguez ${ }^{1}$, Julio Oleas Rueda ${ }^{1}$, Vinicio Velásquez Zambrano ${ }^{1}$, Felipe \\ Castillo Mafla ${ }^{2}$ \& Ramiro Rosón Mesa ${ }^{3}$ \\ ${ }^{1}$ School of Architecture, Pontificia Universidad Católica del Ecuador, Quito, Ecuador \\ ${ }^{2}$ Red de Unidades Educativas Ignacianas, Quito, Ecuador \\ ${ }^{3}$ Tenerife, España \\ Correspondence: Nataly Revelo Morales, School of Architecture, Pontificia Universidad Católica del Ecuador, \\ 170514, Quito, Ecuador.
}

Received: June 30, 2021

Accepted: September 18, 2021

Online Published: October 24, 2021

doi:10.5539/jel.v11n1p11

URL: https://doi.org/10.5539/jel.v11n1p11

\begin{abstract}
In the School of Architecture at the Pontificia Universidad Católica del Ecuador, we are continuously reflecting on the teaching-learning process in order to offer the best education. The COVID-19 pandemic brings different changes in social, health, work and educative practices, which people have had to adapt to. These new conditions have shifted the perception of life and society, so it has demanded a new perspective to solve problems and meet the challenges that have arisen. It has happened with education, in which all stakeholders have been working to face and manage the educational practice in a virtual modality. Based on teaching experience, the present research is focused on the teaching-learning process in Architecture, considering design workshops during the first years of the major. The purpose of this paper, which uses an action research methodology, is to explore those changes that come about from this process in virtual environments. In this way, understanding architecture's teaching and practice through virtual environments can generate an important impact that can transform the perspective on education in this field in the present and in the future.
\end{abstract}

Keywords: action-research, architecture, face-to-face education, teaching-learning process, virtual environment, virtual education

\section{Introduction}

In early 2020, universities in Ecuador and in several countries around the world moved to fully virtual classes because of the COVID-19 pandemic. In many practical fields, such as architecture, face-to-face teaching has been prioritized to ensure the acquisition of subject-specific skills and concepts. Thus, the context of the pandemic has generated new challenges for architecture teaching which can be addressed through an action research methodology.

Action research (AR) is an innovative way of systematizing one's own teaching practice in emerging contexts. Currently, AR has been used in several areas of higher education, especially to comprehend in depth a phenomenon that has no documented experiences. This methodology allows for an understanding of the acquisition of architecture concepts such as sustainability or architectural design (Kowaltowski et al., 2019), the development of collaborative research for the study of architectural design (Caldwell et al., 2016) or the use of virtual reality for spatial design in architecture (Nisha, 2019).

In this article, we will use AR to delve into the teaching-learning process of architectural design. In general, this process develops spatial conception from the application of basic concepts in architecture. The sudden change from a face-to-face to a virtual modality forced the modification of didactic aspects of the architectural design course. The starting point was the research question: how may one continue an architecture design course from initial planning, designed for a face-to-face modality, and adapt it to a virtual environment with an adequate development of skills and competencies? 


\subsection{Objectives}

\subsubsection{General Objective}

Systematize the experiences of the teaching-learning process of Architecture workshops in virtual environments, through the development of an action plan that allows considering guidelines and strategies for the teaching of Architecture in this modality.

\subsubsection{Specific Objective}

- Analyze the academic experience in initial, conceptual, and technical Architecture workshops.

- Reflect on the differences between a face-to-face and a virtual modality in the teaching-learning process in Architecture.

- Generate recommendations for adapting Architecture workshops to virtual environments.

\subsection{State of the Art}

\subsubsection{Educational Paradigm}

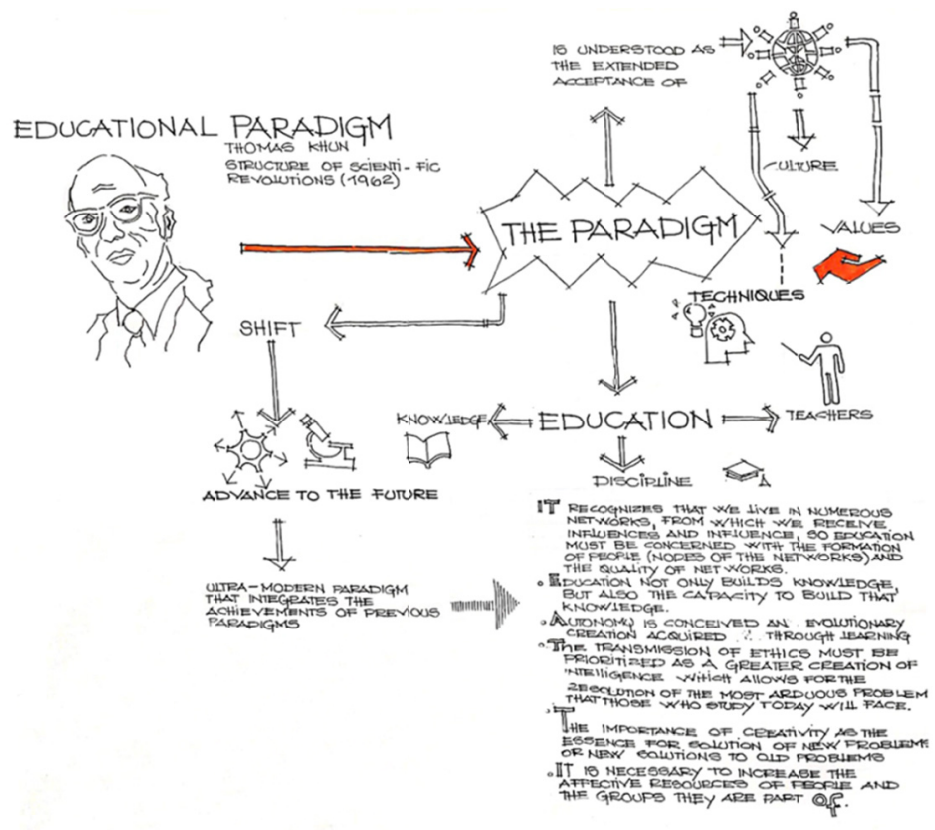

Figure 1. Educational Paradigm — Own illustration

The development of a discipline is based on paradigms. For Thomas Kuhn, in his work The Structure of Scientific Revolutions (1962), paradigm is understood as the extended acceptance of beliefs, values and techniques by a scientific community. The cultural context determines the way a given science acts, interacts, and innovates.

In the case of education, paradigms provide a way to understand and proceed in a formal educational space. It shapes how professors approach their discipline, what models and methodologies they use to transmit knowledge, and what to focus on in order to achieve learning. We are facing unprecedented changes and radical uncertainties. Since paradigms depend directly on the cultural and historical context, this series of changes force us to think about a change of paradigm also in education.

In the past, transmitting information was fundamental because it was rare, and it was the role of schools and universities to provide it. However, providing information to students is no longer an essential function of the professor because an enormous amount of information is now easily accessible. Now "people need the ability to make sense of information [...] and above all, to combine many bits of information into an overall picture of the world" (Harari, 2018, p. 324).

Because it is uncertain what scenarios students will face tomorrow, several authors agree that teaching should 
focus on competencies rather than transmitting already structured information. Some essential competencies for the 21 st century are critical thinking, communication, collaboration, and creativity.

It is necessary to define a paradigm that emphasizes responding to the cultural changes that we are facing. Marina (2017) mentions certain features of an ultra-modern paradigm that integrates the achievements of previous paradigms:

- It recognizes that we live in networks, which influence and encourage us, so education must be concerned with the formation of people (nodes of the networks) and the quality of networks.

- Education not only builds knowledge, but also the capacity to build that knowledge.

- Autonomy is conceived as an evolutionary creation acquired through learning.

- Creativity is essential for solving new problems or finding new solutions to old problems.

- The transmission of ethics must be prioritized as a greater creation of intelligence which allows for the resolution of the most arduous problems that those who study today will face.

- It is necessary to increase the affective resources of people and their networks.

\subsubsection{Architecture Learning: Project-Based Learning and Problem-Based Learning}

Project based learning differs from problem-based learning, particularly on the goals which are set for the product which will be graded. Both address real-world problems that must be solved through investigation, thought, reflection, and a product that demonstrates the benefits of the proposed solution. In the beginning levels of an architecture degree, workshops are built on project-based learning.

On the other hand, problem-based learning requires all participants - students and professors - to define the goals and products which must be presented at the end of the workshop. The procedure, methods, and product or products may differ depending on the limits that define the open-ended design exercise. In this case, the skills and prior knowledge of students allow them to work more independently, where the professor becomes part of the team or teams which are involved in the teaching and learning process.

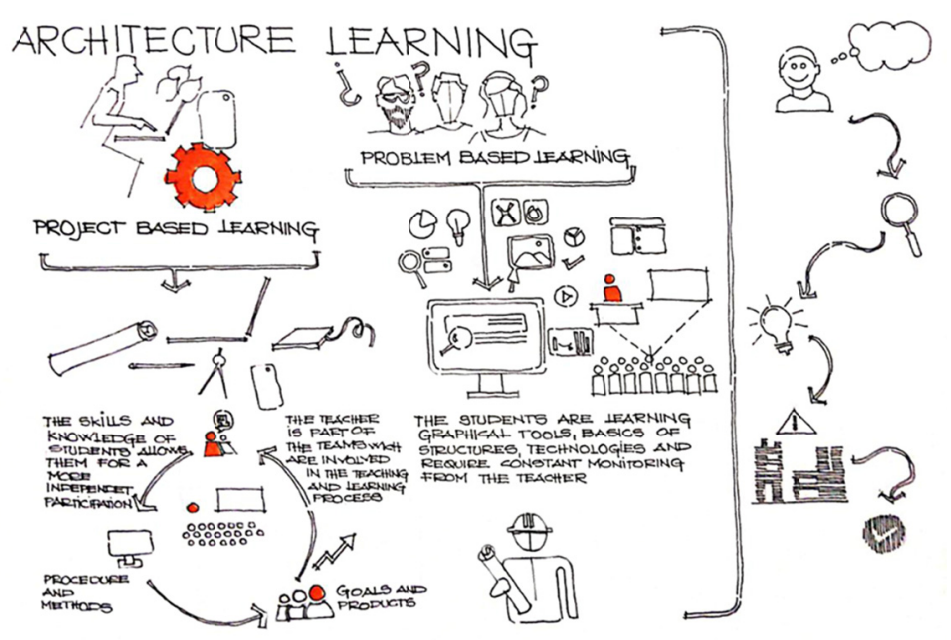

Figure 2. Architecture Learning-Own illustration

\subsubsection{Face to Face and Virtual Learning in Architecture Workshops}

Due to its nature, an architecture class needs specific requirements within a teaching and learning model. Even though the teaching and learning process is resolved initially from a person's interest in learning rather than from a person's interest in teaching (Schank, 1986), the teaching activity remains primarily important. Schön (1992) defines an architecture workshop's teaching and learning process as the thought of the action, which can also be transposed as the learning of the action.

As mentioned before, the teaching-learning process that an architecture workshop class requires includes multiple variables. For a student to comprehend the complexities of architectural space, a professor must draw 
over plans and modify 3D models. In this way, students can understand the spatial operations involved through the intervention in their design proposal. Thus, the student needs the guidance of a professor who is able to perform tasks which must be carried out in a delicate but emphatic way, explaining the benefits of the process completed in class.

In virtual scenarios through e-learning, an architecture workshop class brings the same concerns, but includes the difficulties of overcoming distance. Human and technological limits need to be addressed with the same - and perhaps even more - attention from the professor. By LMS, video conferences, CAD, and 3D modeling software, both students and professors need to exchange proposals and corrections in an efficient manner.

\subsubsection{Didactic Strategies}

Didactic strategies refer to educational resources that involve teaching and learning. Within architecture workshops, a variety of strategies and techniques are applied, such as architectural design software, gamification, and soft skills aimed at collaborative work and self-regulation. Related to virtual education, these strategies have allowed students to obtain knowledge from different ways of learning.

\section{- $\quad$ Architectural Design Software}

Nowadays, a clear dependence on technology and software systems exists in all human activities. It is important to understand that a PC is designed to help to execute a broad range of activities and purposes through the integration of symbols and functions understandable to people. A PC manipulates, exchanges and stores data, externalizing it for users. IT software manages a detailed sequence of instructions given by a person to fulfill a certain need (Segret, 2013).

\section{- $\quad$ The Design Process}

Design is a technical-creative activity focused on the generation of useful and aesthetic objects or spaces. Design is a process of symbolic representation, in which notions such as shape, figure, concept, object, structure, building, or architectonic space are traced (Universitat de Valencia, 2020). This process could differ depending on the application area, nevertheless the steps of classic process design are:

- Definition: main characteristics and properties of what is about to be designed are established.

- Modeling: creation of an element which represents and satisfies the needs, requirements, and specifications of the project.

- Detailed drawing: representation of objects which are expected to be built through graphic representation. The sheets must consider enough technical information and data that allow it to be feasible.

- Prototyped: the previous process of the building stage that helps to detect modeling mistakes, used to validate components or properties.

- Proofing: specific processes in chain manufacturing, where prototypes are done to valid models.

- Documentation: generating information to build an edification without the need of additional data, including installation schemes, description of systems and components, among others (Universitat de Valencia, 2020).

- $\quad$ Software and Building Information Modeling (BIM) Methodology.

BIM methodology allows for a comfortable design, construction, and management of edifications, understanding them from how they were built to how they work. This methodology is based on an exchange of information about the project in a clear manner. The BIM methodology incorporates various methodologies and tools with the aim of preventing loss of information throughout the project's life (González et al., 2014).

\section{- $\quad$ IT applications}

An IT application is a type of software that allows users to carry out specific tasks through an IT device (Desongles \& Moya, 2006). The word "application" involves technology with a practical aim which influences the context to which it is related. IT applications should make different tasks easier. This means that technology must be placed at the service of people's needs. In last two decades, the use of IT applications has generated a huge social impact because of its multiple functions including: information, entertainment, social and affective relationships, and electronic commerce. In this way, IT applications have changed people's habits and have become sociological phenomena on a global scale. 


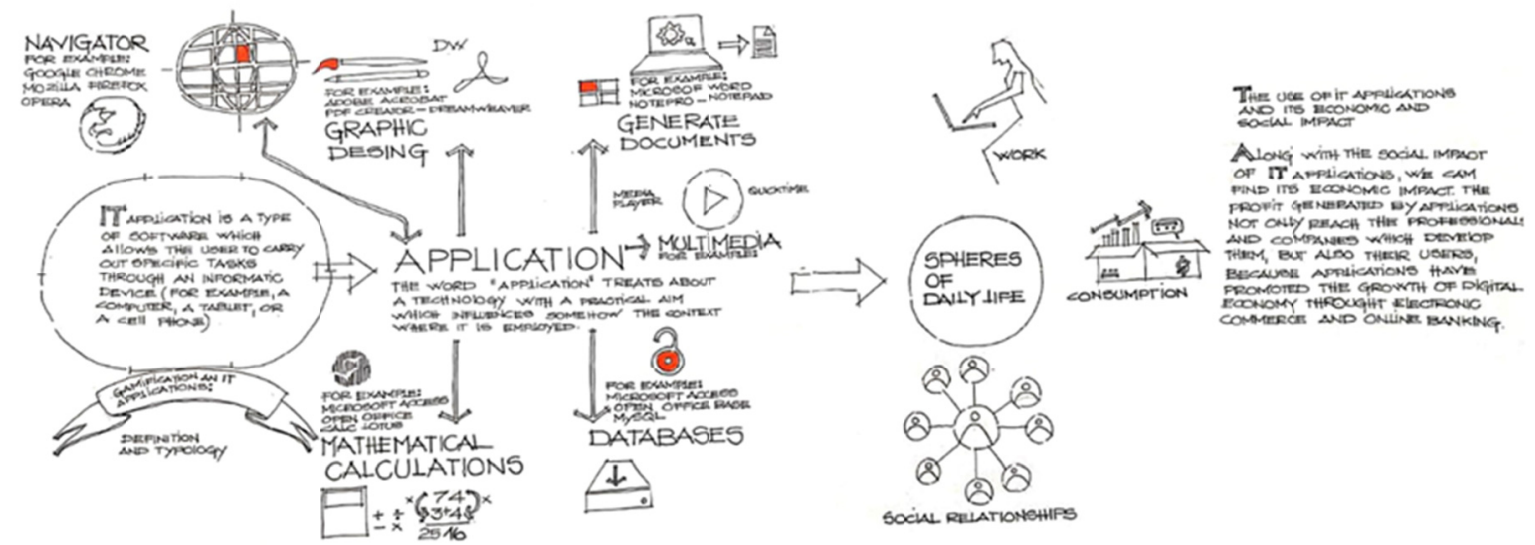

Figure 3. IT applications-Own illustration

- $\quad$ Soft skills for collaborative work and self-regulation in virtual environments

Soft skills vary with diverse definitions and though it is not the main focus of this study to analyze each of them and determine the correct one, it is rather important to justify its relevance in virtual environments. Ruiz-Morales, García-Garcia, Biencinto-López and Carpintero (2017) identify them:

[...] as a web of complex know-how (knowledge, abilities and skills) that combined with attitudes (motivation, interest, disposition, etc.) and values, enable someone to act assertively in a range of situations to tackle or solve situations likely to arise within the scope of the human being (individual, family, academic, organizational and social) (p. 3).

Some of the most common skills include leadership, teamwork, stress management, communication skills, the ability to handle interpersonal relationships, independence, creativity, among others. Technical or instrumental skills are not necessarily included, although as the increasing use of Information and Communication Technology (ICT) gains ground on educational and social relationships, managing and handling them is crucial when developing soft skills in virtual environments.

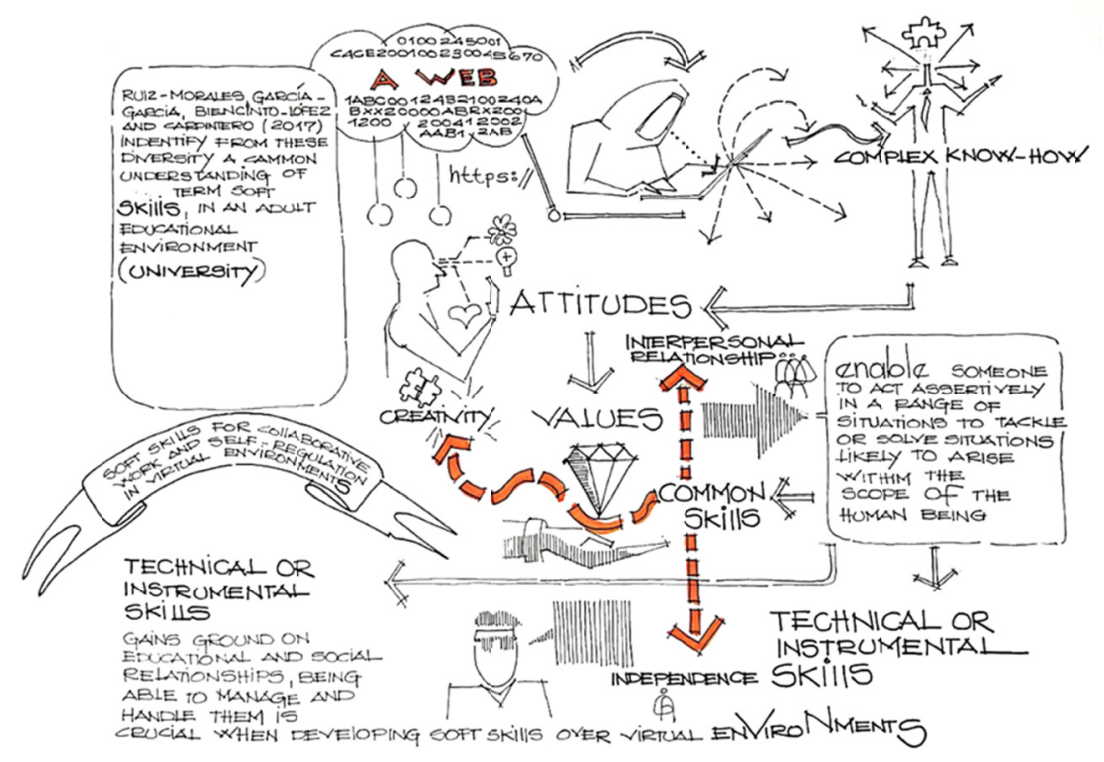

Figure 4. Skills and Attitudes-Own illustration 


\section{Method}

\subsection{Action Research Methodology}

Recently, education has extended theory to practice, aimed to improve educational experiences and communities. There are different types of practical reflection, but one of the most relevant is action research. According to Oakshott, it refers to the kind of reflection based on diagnosis (Elliot, 2000).

Taking a closer look at action research, it implies analyzing and understanding the different personal and social situations that professors experience in their educational practice. This comprehension allows them to make different decisions and take certain actions to be implemented in learning spaces. In addition, this collaborative process needs the participation of professors and students to transform education. It also requires questioning the traditional methods and discussing the possible changes to apply in this process. In summary, it generates different points of view and discussions about the information, planning, and analysis that are involved in a reflective teaching practice.

The process of action research methodology consists of four steps: the research problem is detected and diagnosed; a plan is drawn up to solve the problem; the plan is applied and its results are assessed; finally, feedback is given, with a new diagnosis and a new process of reflection and action. Action research applied to the teaching-learning process of Architecture workshops in virtual environments is developed through the following ideas:

- $\quad$ State an essential question that directs the research, in order to manage remote education in the architectural design workshop.

- Communicate the experience as a script that refers to the process that was done, describing what, how, and why the professor does his/her own process and who the participants are. The script of experience is developed in four steps:

- Initial planning for face-to-face (F2F) education: How the workshop was planned under F2F conditions, relating the context, level of knowledge, process, and contents.

- Experience and adaptation from F2F to virtual learning: Talk about the changes that professors implement in their working process, pointing out digital applications, methodologies, and accompanying strategies and feedback in the virtual environment.

- Students' experience about virtual learning: Talk about students' adaptation to this virtual environment, considering challenges, problems, and solutions that were present at the time.

- Soft skills: Show the importance of soft skills in the teaching-learning process for professors and students, even more so in remote education where there is no physical contact.

- Reflection on learning opportunities, related to the theory that was reviewed in the state of the art:

- Reflection on significant moments, activities, and situations that were experienced by the professors in the process, and also the collaboration between them.

- Reflection on the influence of the work with the students, the context and circumstances that impact in their development, and the evolution of the work.

- Approach to other questions and steps to improve the teaching-learning process experience.

- Individual and general reflections to understand the experience and process in virtual environments of the architectural workshop.

- Create a project proposal directed to architectural workshop in virtual environments (Action Plan), that allows the team to answer the essential question through other inquiries like:

- What objectives does the professor want to achieve?

- What actions can be taken to answer the question?

- What resources can be used to manage a virtual environment?

In conclusion, action research is a way to understand teaching as a research method through experience, reflection, and practice (Bausela Herreras, 2004). It is not only about the resolution of problems, but also personal reflection, in order to plan and improve one's own educational practice, considering all the factors involved in the teaching-learning process in the complex context of architectural workshops. In this case, this methodology allows for an organized process of experience and reflection in Architecture, producing an action plan that defines and delimits the method to carry out a workshop in a virtual environment. 


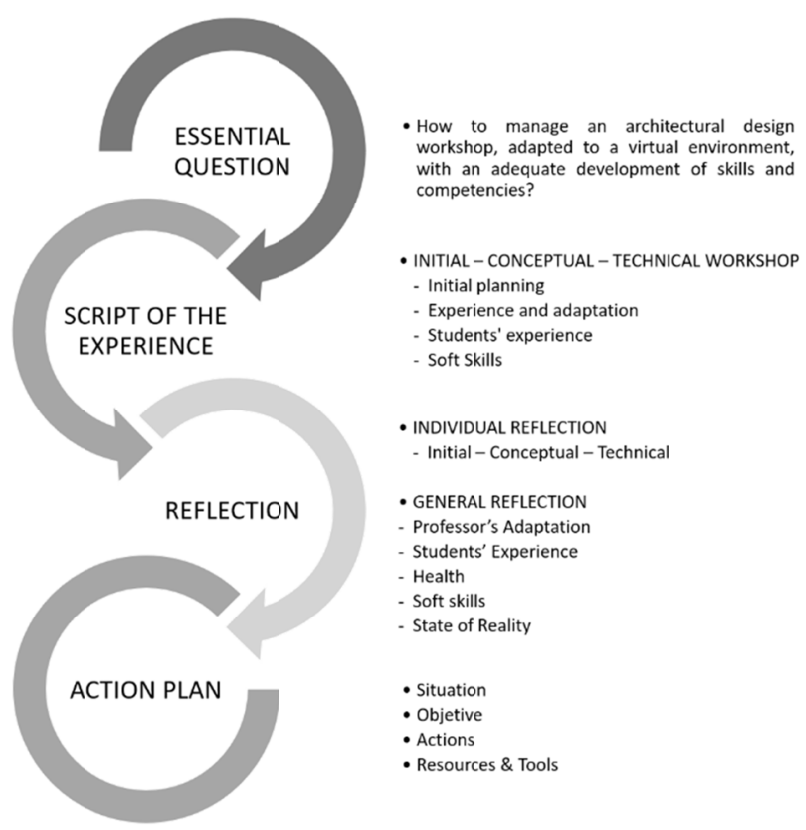

Figure 5. Methodology—Own illustration

\subsection{Matrix: Frequency and Intensity of Academic Parameters}

The qualitative matrix is designed to simultaneously measure frequency and intensity of several academic parameters named sub-categories, placed within four main principal categories. The categories are all measured at the basic, theoretical, and technical levels, and finally all of them are compiled within a single chart, which allows for visualizing the effect of each sub-category.

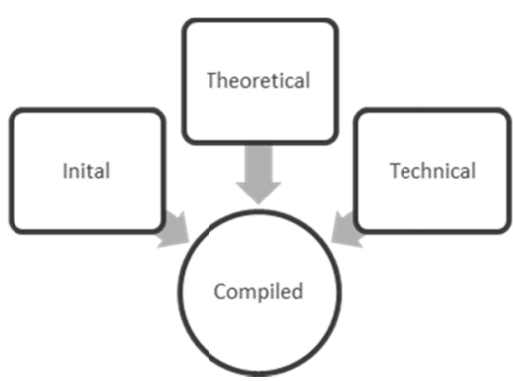

Figure 6. Categories' scheme-Own illustration

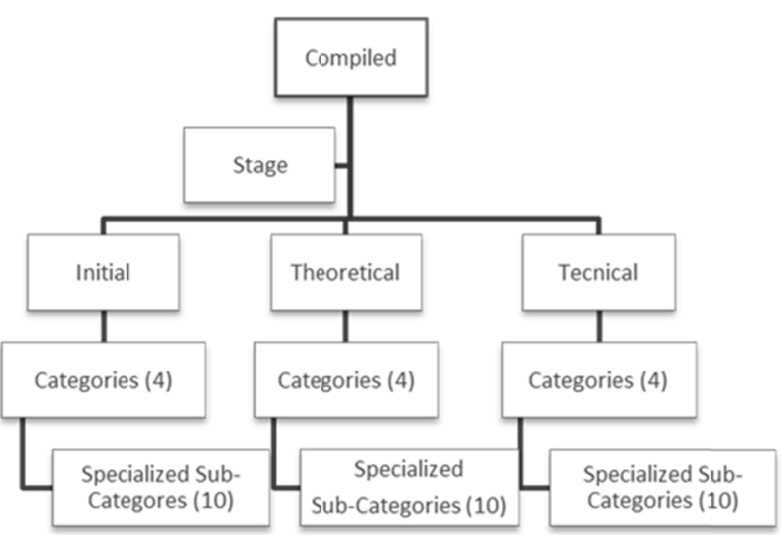

Figure 7. Categories' structure-Own illustration 
There are four main categories that measure the experience of each stage:

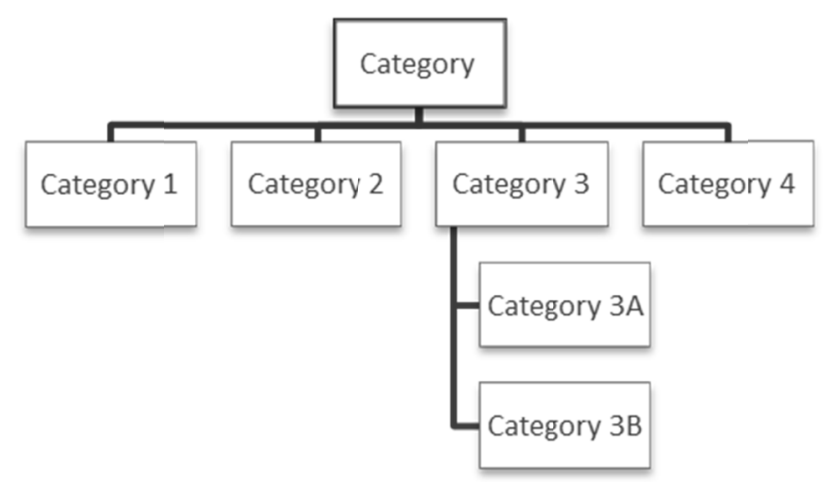

Figure 8. Categories of each stage-Own illustration

Each category has several specific sub-categories which contribute to the overall understanding of academic and student situations in each main stage. Each sub-category has a horizontal scale subdivided in five frequency cells, which allows for measure recurrence. Items in the left column occur less freequently, while items in the right column indicate more frequent occurance. Each individual category is rated on a numerical scale (1 to 5), which reveals the grade of incidence of each sub-category linked to the grade of frequency. In order to make the information in the matrix more understandable, the numerical scale of intensity is associated with chromatic colors.

Initial head-on plan

\begin{tabular}{|c|c|}
\hline $\begin{array}{l}\text { Development of professional } \\
\text { relationships }\end{array}$ & \\
\hline $\begin{array}{l}\text { Development of inter-personal } \\
\text { relationships }\end{array}$ & \\
\hline Group integration & \\
\hline Face to face reviews & \\
\hline Photograph on the site & \\
\hline Physical model & \\
\hline Printed plans / drawings & \\
\hline Field trips & \\
\hline Face to face group work & \\
\hline
\end{tabular}

Figure 9. Category 1: Initial head-on plan-Own illustration 
Professor's virtual adaptation

\begin{tabular}{|c|c|}
\hline Due date extensions & \\
\hline Individual tutoring & \\
\hline Group tutoring & \\
\hline Methodological adaptations & \\
\hline Changes in number of planned jobs & \\
\hline Changes in the subject schedule & \\
\hline Commutation adaptations & \\
\hline Job extension adaptations & \\
\hline Job evaluation adaptations & \\
\hline Feedback adaptations & \\
\hline
\end{tabular}

Figure 10. Category 2: Professor's virtual adaptation-Own illustration

Students' experience

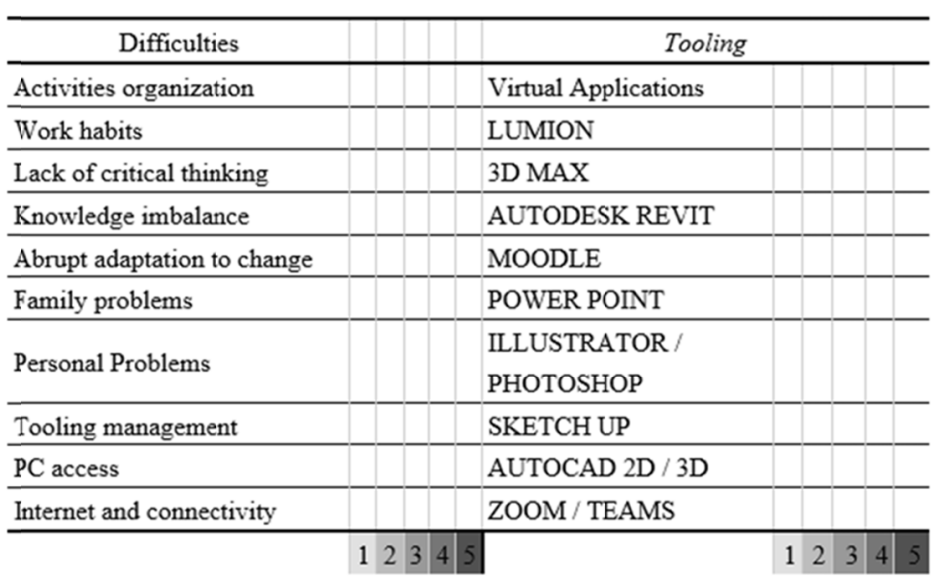

Figure 11. Category 3: Students' experience-Own illustration

Soft Tools

\begin{tabular}{|c|c|}
\hline Encourage & \\
\hline Empathy & \\
\hline Team work & \\
\hline Leadership & \\
\hline $\begin{array}{l}\text { Effective } \\
\text { communication }\end{array}$ & \\
\hline Punctuality & \\
\hline Trust in the group & \\
\hline Self-confident & \\
\hline Respect & \\
\hline Maturity & \\
\hline & \begin{tabular}{lll|l}
1 & 2 & 3 & 4
\end{tabular} \\
\hline
\end{tabular}

Figure 12. Category 4: Soft Tools-Own illustration 


\subsection{Applied Methodology}

Beginning levels of an Architecture degree are primarily based on project-based learning. In this model, the products, formats and even the design process are defined by the professor and must be implemented by the students. The professors' ability to communicate and share knowledge in these levels is essential and diverges from abilities associated with higher levels where the complexities are different. Three different levels have been selected for this study, which encompass the initial and basic aspects of an architecture school. The first level receives students who have almost no knowledge about architecture. This workshop focuses mainly on basic theory and space composition. The second level that has been chosen for this study presents a conceptual approach to Architecture, where students must justify their architectural discourse based on the coherence of the design process and the final product. The third level is based on technology as the path to resolve construction and architectural problems. It is necessary to remark that all this knowledge is summative for the following levels. The major is deeply rooted in initial architecture workshops; therefore, it is essential for professors and students alike to adapt in the best way possible from F2F learning to e-learning. Because of this, this research is focused on the experience with and reflection on the teaching-learning process of these architecture workshops in virtual environments, based on action research methodology.

\subsubsection{Essential Question}

How can one manage an architectural design workshop, adapted to a virtual environment, with an adequate development of skills and competencies?

\subsubsection{Script of Experience}

\section{Initial Workshop}

\section{- Initial planning for F2F education}

When students arrive from high school at the university, they face a new rhythm of study and approach to different topics that will be covered during the major. In the case of the F2F initial architecture workshop, it has been relevant to create an atmosphere of clarity, confidence, and support that provides students with security from the beginning. The most significant aspect of F2F education is strengthening the interpersonal relationships among classmates and professors, so the group becomes unified during the academic period.

In the initial workshop, there are between 10 and 15 students per course. The knowledge level with which students start the major is basic and intuitive. As for the contents, the initial workshop is focused on applying composition in two and three dimensions. It starts with learning to observe, then to abstract, and finally to compose. This process allows students to understand the volume and approach to the architectural space.

\section{- $\quad$ Experience and adaptation from F2F to virtual learning}

Due to the situation brought about by the Covid-19 pandemic, which included confinement, many aspects of life like education were affected and had to be changed. Face-to-face has been the traditional way of teaching architecture, but during this time, remote teaching has been used as a primordial resource. In this line, the initial workshop classes were conducted through Learning Management System (LMS), with synchronous and asynchronous elements, through study guides and resources on the platform. Also, different applications and software were used to continue with the objectives of the course.

Those exercises that required visits to work sites or that implied contact with the city had to be rethought. Also, since it was not possible to have access to materials, the practical work was carried out through recycling as part of the process of experimentation on physical models, and 3D open access software was used to present projects digitally. On the other hand, accompaniment and tutorship increased with the need to follow up on the process that students carried out outside of classes. Finally, evaluation and feedback were handled clearly, considering headings and evaluation aspects, focused on the process developed by the students.

\section{- Students' experience of virtual learning}

In addition to all the changes that were carried out during the academic period, it is important to point out the adaptation of students to virtual learning. In the first instance, attendance was normal in the class schedule. Students did not have continuous absences, except for occasional cases. One of the most frequent drawbacks was connectivity, since the internet connection or access to a single-use computer became difficult for students during this time. However, if students could not connect to class, they could access reviews and solve any doubts during the tutorships. Also, the class recordings allowed them to receive the material asynchronously.

On the other hand, some students went through some troubles due to personal and family situations, which were important to recognize in order to provide support and follow-up, to prevent these situations from affecting their 
academic and personal development. Finally, the handling of virtual tools was also a challenge for the students during this time, considering that they were not trained in their use, and it was necessary to employ both the virtual classroom and the architectural software. Due to the situation, the presentation of projects was done in a mixed way, digital and manual, so that learning could be handled better.

\section{- $\quad$ Soft skills}

It refers to those human skills that enable a relationship and interaction between people. As part of this remote education, the importance of teamwork, leadership, empathy, effective and affective communication has been further perceived in both students and professors. In the initial workshop, being new students in university, they need to feel in a supportive and confident environment that should be provided by professors, who oversee giving them not only technical but also human tools for their comprehensive development. Considering that there are different circumstances, personalities, and ways of learning, it has been important to personalize the teaching experiences, resulting in a process full of support, clear communication and openness to changes to reach quite favorable results.

\section{Conceptual Workshop}

\section{- Initial planning for F2F education}

As the academic period was planned to be taught in a F2F education model, it began as a regular period, involving the sequence of exercises, schedule, and other activities of an architecture workshop. Students cursing the conceptual stage of the career began to understand the intentions of architecture space and handle drawing methods, analog and digital, with more solvency. The architecture workshop is structured by three different design exercises, all of them focused on constructing an abstract idea prior an architectural design. The first exercise involves a quick design made on small groups to evaluate knowledge and thought capabilities. The second exercise takes several weeks; it requires a site visit and meeting with the social actors that are involved. The third project has a higher complexity and major requirements in the final product. All these exercises have one objective: construct reflective thinking to solve a problem within a real context to produce coherent and innovative architecture.

\section{- $\quad$ Experience and adaptation from F2F to virtual learning}

As COVID-19 advanced throughout the world, governments set quarantine policies for safety and stopping its spreading. The academic period took place when those policies were applied, thus adaptations were needed to continue with education. Remote learning was established as the viable solution which can permit an ongoing F2F learning experience switch to virtual learning.

Initially, classes remained on the same schedule and were given primarily by synchronous communication platforms. Group and individual exercises also remained the same, so students needed to organize and coordinate virtual sessions to advance though the design process. During class hours, students exposed their work to all their peers and professor, to obtain a constructive critic within the design process. Recorded classes remained on the respective LMS for asynchronous visualizations, available for all students. Classes required softwares which allowed students and professors to interact within the complexities of distance, computer capabilities and internet access. Furthermore, the complexity of abstract thinking, to produce conceptual architecture, was a challenge that required immediate response from professors. On the other hand, CAD tools and 3D open access software were used to produce 2D drawings and 3D models respectively, to understand the space intentions of the project. Critics, corrections, and modifications in class hours were primarily carried out through these tools

\section{- $\quad$ Students' experience of virtual learning}

Students' participation and attendance were erratic throughout the quarantine. Half of the students attended classes regularly while the others presented different issues, which required different answers from professors and the university. Most students claimed to have limited internet access due to reasons such as a weak signal in remote areas, no computer, one shared computer, and internet service failure. Most of these problems were resolved by tutorships requested by students, which required extra time for professors. Also, emotional problems were common in students due to external circumstances. It affected the correct development of the learning process, requiring assistance from both the institution and the professor for special cases to tend to their needs.

\section{- $\quad$ Soft Skills}

Students and professors required an additional effort to bring out the best in the current circumstances. Soft skills were primordial to culminate the academic period without major complications. Characteristics such as empathy, leadership, companionship, correct communication, and personal discipline were the most important to manage 
conflicts and solve problems in remote learning. The results were students that not only learned about conceptual architecture but also about human relations and personal behavior.

\section{Technical Workshop}

\section{- Initial planning for F2F education}

Students in the technical stage already have a basic knowledge and understanding of structures and constructive systems on concrete, wood, and steel, and some design experience, including theoretical and formal-volumetric aspects. Additionally, at this stage the students have an acceptable command of architectural software tools such as $\mathrm{CAD}, 3 \mathrm{D}$ open access software, digital graphic tools, among others. The architectural exercise implies collective and individual work. Each student was asked to develop approximately $1,600 \mathrm{~m}^{2}$ of a building design, with a chart of spaces related to the initial analysis. The students were required to illustrate their design development twice per week with architectural drawings, volumetric and structural scaled models. In this stage the designer's explanation about the decisions made on shape, distribution, orientation, proposed materials, and structural scheme is essential to get feedback from the others.

\section{- $\quad$ Experience and adaptation from F2F to virtual learning}

Going from F2F to virtual education forced the implementation of unplanned methodological changes. Web connectivity and synchronous communication tools were crucial to continue with the academic process. Cloud storage and asynchronous information tools were fundamental to keep the collective and individual design process saved chronologically, permitting moving forward and backward in the design process. General aspects of architecture design were covered collectively. However, many specific aspects were approached individually through the implementation of synchronous online classes. 2D \& 3D architectural softwares were useful tools which allowed students model and understand the architectural space and structure, replacing the use of physical scaled models. To achieve significant results, it is mandatory to keep chronological files with the project development. In general terms the individual project is distributed in two main stages:

- Architectural approach: development and definition of the complete project through the architectural program, spaces, horizontal and vertical connections, volume interaction, heights, proportions, materials, clear and opaque enveloping, pedestrian and vehicular access, among others.

- Constructive detailing stage: development of how the different construction elements are connected between them, and how they are supported and sustained by the main building structure.

Remote education at this stage implies a higher level of class preparation and aspects related to the evaluation of the design of the project, including the ideas and concepts that do not necessarily have a quantifiable result. To properly develop a project, the followings aspects were considered:

- Direct and indirect relation approaches of the project with the environment (natural and manmade), including the use of natural lighting and ventilation.

- Interpretation of local technologies applied in a contemporary architectural design.

- Understanding of physical concepts and structural principles (balance, resistance, structural behavoir, among others).

- Knowledge of local materials in terms of the rational use of them.

- Ability to communicate about architecture, volumetric composition, architectural drawings, technical-constructive information, rendering, and photomontage resources, among others.

The development of the project is presented weekly by all the participants through screen sharing using synchronous communication tools. Each student has a time limit of ten minutes to explain the progress and decisions made and another ten minutes to receive feedback from other students and the professor. In this way, information sharing and knowledge allotment are guaranteed.

\section{- $\quad$ Students' experience in virtual learning}

Professors and students had to adapt rapidly to remote education. Communication and interaction changed because of the physical distance. However, there were no substantial changes in class participation and the sharing of information and knowledge. Most of the problems were related to internet connectivity and personal problems. The pandemic produced by Covid-19 generated the mandatory confinement at home for a long period of time, in some cases affecting productivity and mood. In this regard, the support given by the professor and classmates was fundamental to overcome the temporal emotional downturn.

- $\quad$ Soft Skills 
It was important to manage a healthy, proper, and productive working environment, where empathy, collaboration, sharing, and support among all were basic values that must be developed and constantly improved. Now more than ever, the personal ability of all to listen and understand others was fundamental, in order to achieve personal and shared objectives.

\section{Results and Discussion of Learning Reflection}

\subsection{Individual Workshop Reflection}

\section{- $\quad$ Initial Workshop}

The initial workshop planning implied F2F contact because it was the way to enroll, motivate, and give the basic tools to students that were beginning their studies. The importance of an emotional environment has been the essence of this workshop, where the first academic and personal relationships at the university are created. All the reviews were done face-to-face, to improve the understanding and feedback on the students' projects. According to adaptation to virtual learning, it was necessary to change the planning of some projects to carry them out in a digital format. In addition, the methodology was focused on virtual media, so the use of videoconferences, online presentations, and reviews changed the way of imparting knowledge to students. Due to the situation, communication and tutorships increased in this time because of the need to solve questions, personalize reviews, and guide the process and development of students' projects.

On the other hand, students went through some difficulties because of the unexpected change. The new situation modified the organization of their activities, the time spent in front of a computer, and the different kinds of problems that they had to deal with, including personal, familiar, and technological circumstances. At this point, it was also necessary to use some digital tools that let the students have classes and also develop their projects. Finally, the development of soft skills allowed for a better management of the circumstances that professors and students had to face. Empathy, teamwork, motivation and respect were the most important skills in the workshop. Students could understand different situations that were happening to their partners, think about solutions, adapt to the change that they were experiencing at that time, and also stay motivated in spite of the situation.

\section{- $\quad$ Conceptual Workshop}

F2F reviews were basic and constant for students to comply with the workshop's requirements. For this propose, drawings (printed or hand drawn) and physical models were required for almost every class. In this process, interpersonal relationships were created where professors and students could learn how to interact with each member of the community. The most important adaptation from the professor was the intensity. The complexities of abstract thinking required in a conceptual workshop had to be resolved between students and professors, providing more time to clear up doubts during remote education. Tutorship was the most common way to tend to students' needs and was given individually or in groups.

On the other hand, students had to adapt in an abrupt manner to the educational changes. Also, students had to solve problems using specific architectural software immediately. They used digital tools daily to be able to present their ideas in classes and tutorship hours. In addition, soft skills were indispensable for an adequate teaching-learning experience. Motivation and self-confidence were fundamental in each class during virtual learning. The human and personal experience, for students and professors, required empathy with the community.

\section{- Technical Workshop}

The technical stage is based on three important factors: teamwork and personal integration, physical and sensory experience on site, and the use of physical models and printed sheets. These aspects could not be fully replaced in the virtual classes, because they affect the academic process. The partial change from the physical models to virtual models was made through $2 \mathrm{D} \& 3 \mathrm{D}$ architectural software, allowing students and professors to comprehend how diverse constructive elements function in space, including structural pieces. Within the student's perspective, immediate changes in working habits and activity organization were necessary, based on a dependence on the PC, internet connectivity, and architectural software. The management of CAD, 3D open access softwares, and digital graphic tools was essential.

Also, personal and familiar aspects influenced the development of the class, and they needed to be addressed through group and individual external meetings. Soft skills took great importance in virtual classes, perhaps much more than in the past. Self-initiative, self-confidence, maturity, and punctuality were essential factors for the satisfactory individual final result of the subject. The circumstances produced by the pandemic obligated students to be more independent and autonomous than in F2F classes, which made constant help and support between students necessary. Internet access and connectivity, virtual information, latest generation architectural 
software, and the self determination of students and professors helped to overcome most of the academic inconveniences produced promptly and unexpectedly by the pandemic.

\subsection{General Workshop Reflection}

\section{- Professor's Adaptation to Virtual Education}

Experiences in virtual environments have provided valuable lessons that can eventually be adapted to the new F2F education. It is evident that more time and space are required to work on emotional aspects with students. Also, key aspects of the classes have been modified, adapting methodologies, organization, and teaching methods to virtual modalities, which are present in the current context.

Tutorships allow a space of support generally focused on academic aspects. They are used to solve doubts about specific subjects, to go deeper into concepts or procedures of the activities done, or to coordinate operational aspects. However, it has been shown that tutorships are also spaces to work on emotional aspects that students experience during quarantine. Therefore, professors should be sensitive to understand the different reactions that students may have and generate a direct emotional link with them.

Regarding class management, professors must differentiate that the virtual modality cannot be managed in the same way as face-to-face. It has been shown that virtual environments require creative classes involving new resources, platforms, and applications to manage learning better. An example of this is the Flipped Classroom Methodology, which allows students to consolidate key concepts of the subject in asynchronous spaces through a variety of tools. In conclusion, professors have adapted to the new dynamics of remote education. They have implemented different strategies to capture the full attention of students, generating a dynamic environment in synchronous classes and meaningful activities in asynchronous moments.

\section{- $\quad$ Students' Experience during Virtual Education}

Students have also changed their strategies to approach knowledge. The tools that professors involve in virtual learning experiences allow for greater student autonomy, because they are not in an environment where their classmates or professors are constantly present. Besides, the autonomy of students enriches their Personal Learning Environment (PLE), since they find greater guidance from the professor in Virtual Learning Environments (VLE) to manage information more adequately.

It has also been noted, much more so than in F2F learning, that not everyone learns in the same way or at the same rhythm. Virtual environments have facilitated the individual analysis of students, as well as having more spaces to learn from their peers, either through forums, collaborative work, or reflection in synchronous moments. However, it is necessary to balance the use of software and manual activities for the development of skills, especially for first-level students.

- Health

Confinement causes multiple physical and mental health problems. This is manifested in spaces such as tutorships, where many students express personal troubles in addition to receiving academic support. This is a way that satisfies these needs for the moment, but it is necessary to generate other spaces where the psychological repercussions resulting from confinement for both students and professors are treated.

\section{- $\quad$ Soft Skills}

Soft skills affect all stages of learning:

\section{- Contact and interaction}

Professor-student and student-student interaction is preferred in virtual spaces. However, it is necessary that some requirements are met, such as turning on cameras in synchronous classes to manage a better interaction between students and professors to facilitate the teaching-learning process.

\section{- Adaptation}

The adaptation of students to virtual spaces has been quick. For the new F2F classes, a new adaptation period will be necessary to include aspects of virtual spaces that have favored student learning, such as greater autonomy or the possibility of diversifying resources for classes.

- Flexibility

Even though the process of acquiring skills and competencies in Architecture implies practical activities that F2F classes require, many of these exercises have been adapted to a virtual environment without losing the learning outcomes. This process can be incorporated in the return to F2F classes. 


\section{- $\quad$ State of Reality}

Many organizations will incorporate various learning experiences acquired in recent months with the almost exclusive use of virtual environments. In the case of universities, it is necessary to analyze the need to generate several spaces for reflection among the entire educational community. It is important to review all favorable aspects that have contributed positively to learning and that can be maintained in a new F2F education, considering the particularities, subjects, and the social and economic problems that will be faced in the future.

\subsection{Action Plan}

The following action plan is set up as a result of the experience with and reflection on remote education in architectural design workshops through virtual environments. It considers the most important situations of this transformation, along with its objective, actions, and resources in order to provide a broad view of the work done:

Table 1. Action plan

\begin{tabular}{|c|c|c|c|}
\hline Situation & Objective & Action & Resources \& Tools \\
\hline Connectivity & $\begin{array}{l}\text { Adapt connectivity tools through } \\
\text { diagnosis, planning and } \\
\text { communication, creating adequate } \\
\text { interaction spaces and ways in the } \\
\text { virtual environment. }\end{array}$ & $\begin{array}{l}\text { Connectivity status diagnosis } \\
\text { Computer, internet, tablet and/or cellular } \\
\text { phone } \\
\text { Virtual sessions planning } \\
\text { Classes through virtual tools } \\
\text { Session recordings } \\
\text { Didactic resources made through apps } \\
\text { Communication channels } \\
\text { Synchronous } \\
\text { Asynchronous }\end{array}$ & $\begin{array}{l}\text { Synchronous and asynchronous } \\
\text { communication and work platforms } \\
\text { Learning Management System } \\
\text { (LMS) } \\
\text { Virtual databases } \\
\text { CAD and 3D software } \\
\text { Image editors } \\
\text { Digital graphic tools } \\
\text { Educational web applications } \\
\text { Hardware }\end{array}$ \\
\hline Methodology & $\begin{array}{l}\text { Define methodologies and learning } \\
\text { strategies through experience and } \\
\text { practice, which allow the } \\
\text { development of academic activities } \\
\text { in architectural workshops. }\end{array}$ & $\begin{array}{l}\text { Active methodologies: } \\
\text { Learning by doing } \\
\text { Learning by seeing } \\
\text { Project and/or problem-based learning } \\
\text { Inverted classroom } \\
\text { Virtual academic planning } \\
\text { Virtual classroom management } \\
\text { Development of content and activities for } \\
\text { virtual environment } \\
\text { Time management in class }\end{array}$ & $\begin{array}{l}\text { Learning Management System } \\
\text { (LMS) } \\
\text { Synchronous and asynchronous } \\
\text { communication and work platforms. }\end{array}$ \\
\hline $\begin{array}{l}\text { Emotional } \\
\text { aspects }\end{array}$ & $\begin{array}{l}\text { Apply practices of support and } \\
\text { attention to students through virtual } \\
\text { meeting spaces, creating an } \\
\text { environment of trust and expression } \\
\text { in workshops. }\end{array}$ & $\begin{array}{l}\text { Attention to the institution's protocols } \\
\text { Academic support } \\
\text { Collaborative activities } \\
\text { Motivation } \\
\text { Integration } \\
\text { Teamwork } \\
\text { Adaptation } \\
\text { Communication channels } \\
\end{array}$ & $\begin{array}{l}\text { Synchronous and asynchronous } \\
\text { communication and work platforms } \\
\text { Learning Management System } \\
\text { (LMS) } \\
\text { Virtual office } \\
\text { Educational and collaborative digital } \\
\text { applications }\end{array}$ \\
\hline Competencies & $\begin{array}{l}\text { Develop technical and human skills } \\
\text { in students through collaborative } \\
\text { and self-regulation actions, } \\
\text { achieving high learning outcomes } \\
\text { and human and social development. }\end{array}$ & $\begin{array}{l}\text { Collaborative work } \\
\text { Participative work } \\
\text { Self-regulation of knowledge } \\
\text { Metacognition (how learning is achieved) } \\
\text { Formal, informal, self-assessment and } \\
\text { co-assessment evaluation } \\
\text { Peer-to-peer interaction } \\
\text { Use of TICs } \\
\text { Analog and digital creative skills }\end{array}$ & $\begin{array}{l}\text { Synchronous and asynchronous } \\
\text { communication and work platforms } \\
\text { Learning Management System } \\
\text { (LMS) } \\
\text { Educational and collaborative digital } \\
\text { applications }\end{array}$ \\
\hline
\end{tabular}

\subsection{Conclusion}

- According to the research, remote education implied an unexpected change in the way of teaching architectural classes. It meant the adaptation in a resilient manner by students, professors, and institutions. In this case, it has been necessary to implement methodologies related to the sources and needs, as well as 
learning strategies through experience and practice of each stage of the workshop. Also, it has been important to arrange adequate interaction channels in the virtual environment.

- The change to remote education implies a new management of an integrative structure of the curriculum, which would allow for greater efficiency in the work of students and professors. It brings content, evaluation, and methodology together, towards the resolution of a common problem or project. The success in an architectural workshop depends on the contribution from the complementary subjects.

- Architecture is a complex discipline. The student learns from practice and the applicability of knowledge, through the idea of learning by doing, which is also evident in virtual environments. The appropriate use of technology is fundamental to reach this objective. Therefore, a clear relationship between design, technique, techonology, and the regulations applied in the profession is paramount.

- Virtuality has made it possible to recognize that access to information is immediate and in real-time. Students have realized this opportunity to research and find everything in global and inexhaustible sources. It implies the coordinated work between the learning team, professor and students, in order to verify the reliable information that let them achieve the learning results of each workshop.

- The teaching-learning process is directly related to physical and psychological well-being of students. They have other personal and family responsibilities and problems, unrelated to academic development. It is fundamental to generate spaces of trust and interaction within the entire educational community, including the institution. Through the results of the research, monitoring and tutoring strategies as well as the support of the other members of the group are necessary to ensure the achievement of academic and personal objectives. In some way, the virtual modality has let students bring all of these together.

- Concerning professors, the importance of adequate time management has been seen in the preparation of classes, elaboration of academic material, and scheduling of asynchronous work for students to reach the initially proposed learning results. It has implied the development of different methodologies such as: learning by doing, learning by seeing, project and/or problem-based learning, and inverted classroom in order to have an efficient teaching process. It is important that professors be continuously trained, both in teaching-learning methodologies and architectural issues, including software, regulations, and new knowledge to be transmitted to students.

- The virtual model encourages autonomous and collaborative learning, which increases empowerment, self-regulation and group task organization in the student as the main actor in the teaching-learning process. The development of technical and human skills in them is relevant to achieve better learning outcomes and human and social growth. On the other hand, it is necessary that students organize their individual and group activities through collaborative work, participative work, and peer-to-peer interaction, to reach an optimal performance in all of the subjects of the academic period.

\subsection{Recommendations}

\subsubsection{Research Recommendations}

- Virtual education breaks the traditional teaching scheme; it is recommended to be open to adaptations and transformations that the educational environment requires.

- It is important to adapt a physical space for teaching and receiving classes, as well as the necessary technological equipment for teaching and learning architecture.

- It is recommended to organize academic activities and the time that they require to manage time efficiently in class.

\subsubsection{General Recommendations}

- Other levels and lines of research could be included to deepen the results of education in the teaching of architecture.

- Research could be conducted with the same levels for different academic periods, to contrast and evaluate the impact in virtual environments.

- Data collection instruments, such as student perception surveys, could be used to obtain a qualitative evaluation of the information. 


\section{References}

Bausela Herreras, E. (2004). La docencia a través de la investigación-acción. Revista Iberoamericana de Educación, 35(1). https://doi.org/10.35362/rie3512871

Caldwell, G., Osborne, L., Mewburn, I., \& Nottingham, A. (2016). Connecting the Space between Design and Research: Explorations in participatory research supervision. Educational Philosophy and Theory, 48(13), 1352-1367. https://doi.org/10.1080/00131857.2015.1111129

Desongles, J., \& Moya, M. (2006). Conocimientos básicos de informática. Editorial MAD.

Elliot, J. (2000). La investigación-acción en educación. Ediciones Morata.

González, R., Choclán, F., \& Soler, M. (2014). Introducción a la Metodología BIM. Research Gate. Retrieved from https://www.researchgate.net/publication/284159764_INTRODUCCION_A_LA_METODOLOGIA_BIM

Harari, Y. (2018). 21 lecciones para el siglo XXI. Debate.

Kowaltowski, D., Silva, V. G. da, Neves, L., Deliberador, M., Zara, O., Colleto, G., \& Ramos, E. (2019). Action research and architectural sustainable design education: A case study in Brazil. International Journal of Technology and Design Education, 30, 815-836. https://doi.org/10.1007/s10798-019-09525-5

Kuhn, T. S. (1962). The Structure of Scientific Revolutions. University of Chicago Press.

Marina, J. A. (2017). El bosque pedagógico y cómo salir de él. Ariel.

Nisha, B. (2019). The pedagogic value of learning design with virtual reality. Educational Psychology, 39(10), 1233-1254. https://doi.org/10.1080/01443410.2019.1661356

Ruiz-Morales, Y., García-García, M., Biencinto-López, C., \& Carpintero, E. (2017). Soft Skills assessment through virtual environments in the university sector: A narrative review. Revista Electrónica de Investigación y Evaluación Educativa, 23(1).

Schank, R. (1986). Explanation Patterns: Understanding Mechanically and Creatively. Erlbaum.

Schön, D. A. (1992). La Formación de profesionales reflexivos: hacia un nuevo diseño de la enseñanza y el aprendizaje en las profesiones. Paidós.

Segret, R. (2013). Visión general de la informática. Editorial UOC.

Universitat de Valencia. (2020). Introducción a los Sistemas CAD/CAM/CAE. In Expresión Gráfica. Universitat de Valencia.

\section{Copyrights}

Copyright for this article is retained by the author, with first publication rights granted to the journal.

This is an open-access article distributed under the terms and conditions of the Creative Commons Attribution license (http://creativecommons.org/licenses/by/4.0/). 